\title{
INFLUENCE OF GEOTECHNICAL CONDITIONS ON DAMAGE STATES OF GDANSK BAY COAST CLIFF FORMATIONS
}

\author{
Eligiusz Mieloszyk ${ }^{1}$ \\ Mariusz Wyroślak ${ }^{2}$ \\ ${ }^{1}$ Gdansk University of Technology, Faculty of Civil and Environmental Engineering, Department of Rail Transportation and Bridges, Poland \\ ${ }^{2}$ Gdansk University of Technology, Faculty of Civil and Environmental Engineering, Department of Geotechnics Geology and Marine Civil Engineering, \\ Poland
}

\begin{abstract}
A geotechnical aspect of destruction processes of seashores was identified based on the case of erosion of Gdansk Bay Coast cliff formations. Causative factors of landslide were described in the context of natural phenomena, land development and its anthropogenic transformations. Possible directions of theoretical analysis of changes in groundwater relations were indicated.
\end{abstract}

Keywords: coastal cliff, escarpment stability, underground water flow

\section{INTRODUCTION}

The Erosion of coastal cliffs is a natural process. Safe existence of cliff areas is not always associated with huge outlays on protecting structures. A right recognition of destructive factors may help in preparation of an effective shore protection project [9], but an erroneous recognition will not hold back cliff erosion processes [5].

This paper is aimed at indication of influence of geotechnical factors on forming ground sculpture in the region of South Baltic Sea Coast, taking into consideration the case of a landslide occurred at Kamienna Góra ("Rock Hill”), Gdynia. Unquestionably, sea wave impact has the greatest effect on sliding the cliff, if only it is located close to sea. If it is separated from sea by a wide beach the sea wave influence diminishes and the influence of water filtering through the ground from land side becomes the crucial destructive factor.

\section{GEOLOGICAL CONFIGURATION}

In the Gdansk Bay Coast region there are geological formations made as a result of accumulative action of continental glacier, accumulative and erosion action of thaw waters, river waters, denudation and sea deposits, plant-built forms as well as anthropogenic ones [1].

The area of Kamienna Góra is a moraine plateau (hill) of a very differentiated sculpture formed as a result of a nonuniform accumulation of glacier material.

The accumulative end moraine produced a differentiated ground stratification in this area. In the bed, up to $20 \mathrm{~m}$ in depth, there can be found mainly sands, clay sands and also layers or irregular dumping grounds consisting silts and ashes formed after the thawing of land glacier fragments remaining in terrain depressions. Geotechnical investigations conducted in the area of the moraine hill Kamienna Góra showed that there were present fine and coarse sands coming from Pleistocene as well as fine sands of Miocene. Sand series are separated by series of Pleistocene marginal lake ashes or piled-up glacial clays. The grounds are of very different filtration parameters.

For many centuries the primeval shore cliff of Kamienna Góra has overcome substantial transformations due to sea action. In present in some places the cliff has been changed by anthropogenic activity associated with infrastructure development, as well as by mining useful mineral materials. A wide beach separates the moraine plateau of Kamienna Góra from sea. 


\section{EFFECTS OF SEA AND LAND ACTION ON SEASHORE FORMING}

Observations of cliff landslides indicate that the main natural factors causing erosion are the following:

- permanent or periodical attacks of storm sea waves against cliff base [4], as a result of which cliff slope retreats step by step back into the land (Fig. 1),

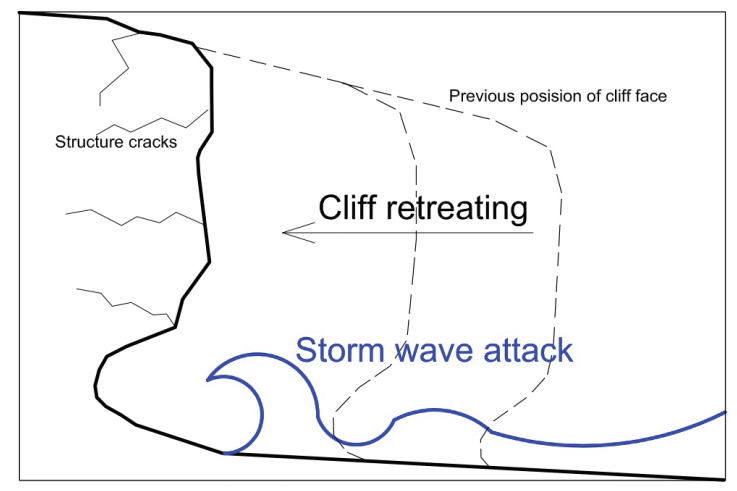

Fig. 1. Erosion of cliff resulting from storm wave attack

- effects of ground mass forces onto sheer slopes, that results in loss of stability and landslides,

- infiltration and flow of underground water from the side of land towards sea, which liquefies the ground and changes its state (Fig. 2).

Among the anthropogenic factors, many effects associated with development of urban and industrial infrastructure may be counted; these are e.g. embankment structures in the form of tight or cavity walls separating natural groundwater flows which concentrate water within determinate cliff areas or accelerate its filtration in ground due to change in water flow direction.

Infrastructure associated with ground surface hardening may also detrimentally affects water-ground relations since water is not capable of gentle filtering into ground and hence it forms fast running surface streams eroding the cliff.

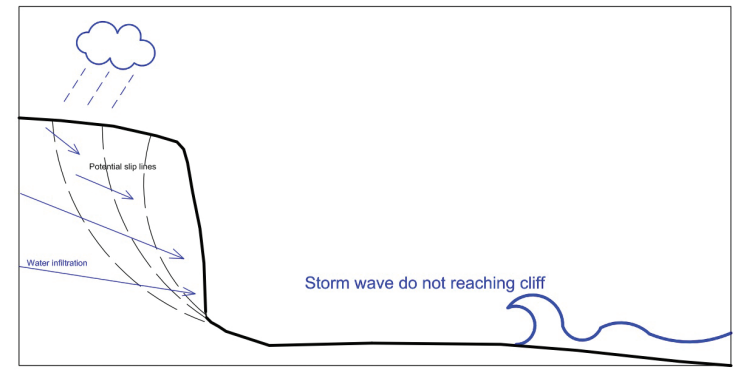

Fig. 2. Cliff erosion due to geotechnical effects from the side of land

Landside effects usually cause also destructions of shore protection structures, for instance such as the damage of cliff protection gabion structure shown in Fig. 3.

The deformations could not be caused by storm waves in view of that the beach is a dozen or so meters wide [11]; their causes should be searched in periodical changes in groundwater relations within the cliff itself.

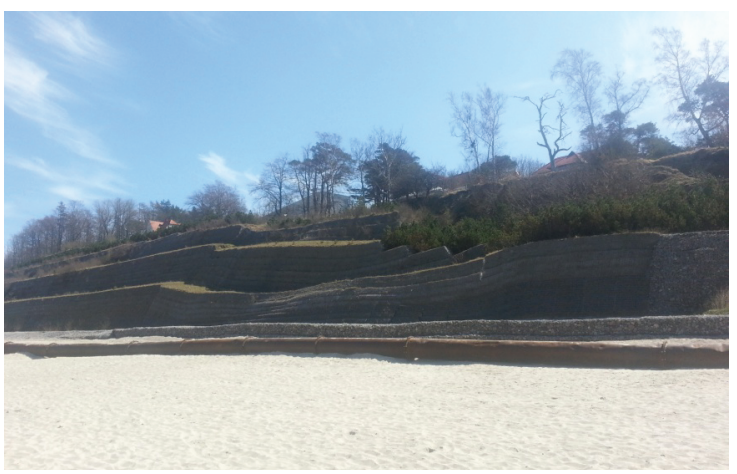

Fig. 3. Deformations of the cliff protection structure made of reinforced ground and gabions (2014) [8]

In the case in question it may be assumed that sea effects are negligible. However, there are local areas where changes in landform features happen periodically as a result of loss of ground stability.

\section{COURSE OF THE PHENOMENON}

In the night from $23^{\text {rd }}$ to $24^{\text {th }}$ February 2017, in Gdynia, below Sienkiewicz Street, a sudden landslide and run-off of ground-water mass occurred from the escarpment. The sliddown and watered ground mass displaced forming a precipice. Simultaneously, the active tongue of the landslide locally deformed the lie of the land, rising the terrain level by $1,5 \mathrm{~m}$ in some places.

A $7 \mathrm{~m}$ fragment of the street pavement and roadway was damaged. A geotechnical consequence of the occurred situation is a new state of force equilibrium spontaneously settled in the ground. The geotechnical investigations of the terrain in question show [10] that this state is not stable and may be changed after subsequent intensive watering the ground. A week after the reported event some water flow sources and symptoms of the significant ground watering were found in the site of the landslide.

\section{CAUSATIVE FACTORS}

The course of the phenomenon indicates that causes of forming the landslide should be searched out in accumulation of water in the sandy ground covering a layer of clayey and ashy ground of a low filtration ratio. In the entire area of the moraine hill Kamienna Góra some quantities of water collected over dump clay inclusions may be expected.

As a result of the critical water pressure produced in pores of the ground, the hydraulic piping flow and its significant pressure occurred, that caused washing away the road embankment and liquefying the ground. This is a frequent cause of building damages associated with changes in ground-water relations, that is described in the geotechnical literature [2]. In the photographic documentation there are visible a hydraulic piping flow canal and a cavern formed as a result of the washing out of 
anthropogenic ground layers placed under the roadway (Fig. 4, Fig. 5a, Fig. 5b, Fig 5c).

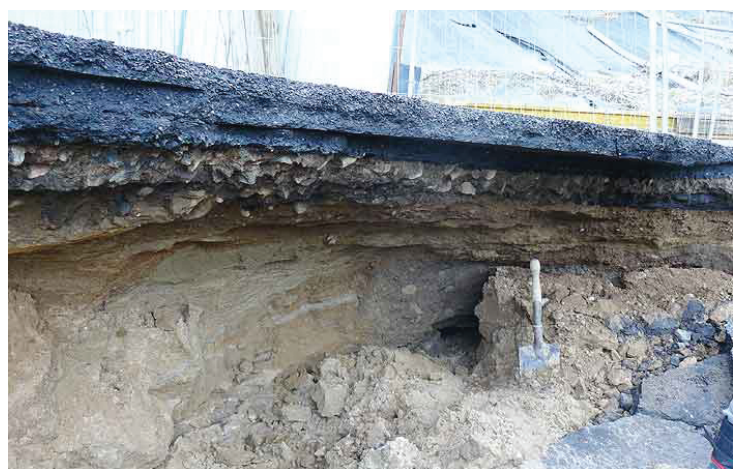

Fig. 4. A cavern and hydraulic piping flow canal revealed after the damage [10]

a)

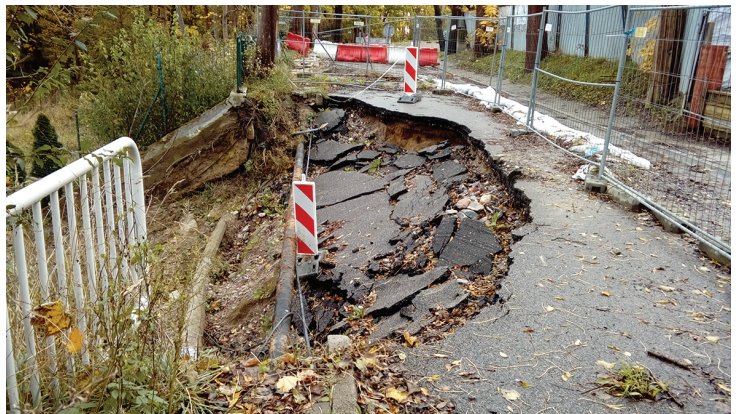

b)

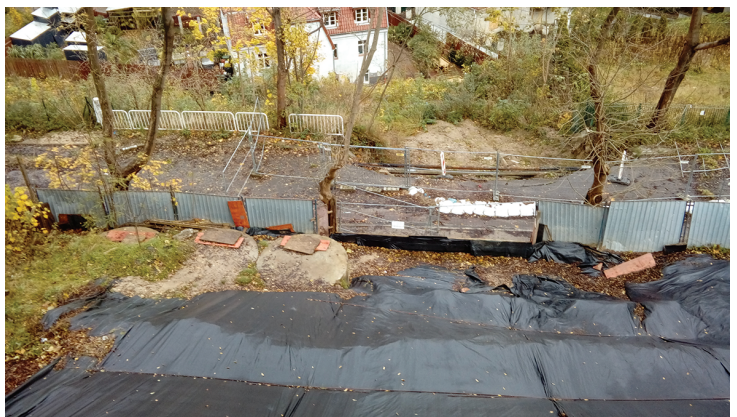

c)

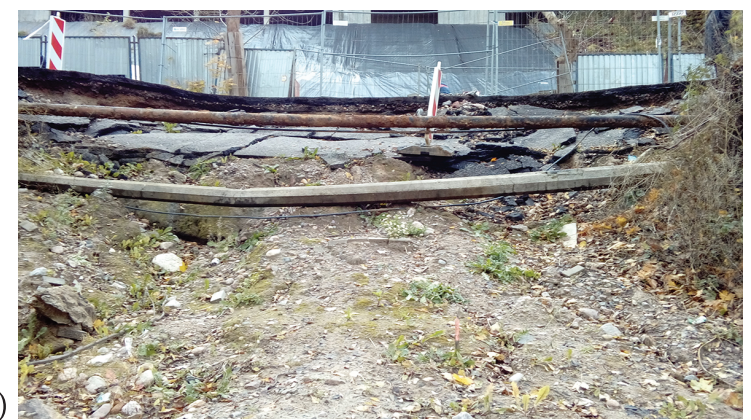

Fig. 5. State of the landslide 8 months after the damage

The geotechnical cross-sections in the line of the landslide have confirmed possible water accumulation in ground lens (Fig. 6). On this basis it is possible to conclude that the geological structure of the base in which ground layers of a higher and lower water permeability alternately appear, helps in forming privileged ways of water filtration in the ground and underground water flows concentrated within a rather small space. In the base there are ashy ground layers which are characteristic of substantially decreased strength parameters in case of watering.

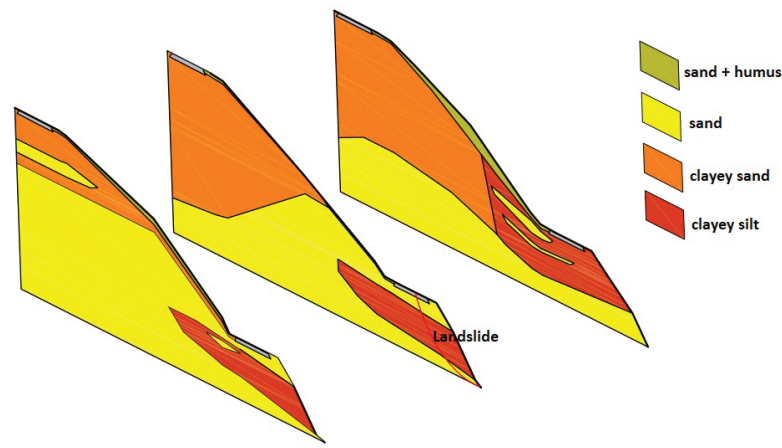

Fig. 6. The geological cross-sections showing stratified grounds of variable filtration ratio within the landslide

The causative factors can be subjected to a numerical analysis by using a mathematical description method applied in hydrology.

The one-dimensional differential equation describing water flow in the non-saturated ground area has the following form [3]:

$$
\frac{\partial}{\partial z}\left(D(u) \frac{\partial u}{\partial z}+K(u)\right)=\frac{\partial u}{\partial t},
$$

where $u(z, t)$ stands for volumetric moisture content in the ground, $t$ - time, $z$ - a coordinate describing the depth in which the phenomenon is analyzed, $D(u)$ - moisture diffusion coefficient in the ground, $K(u)$ - filtration ratio along z-axis. It's worth adding that Eq. (1) describes also many other phenomena which contributed in the damage of the coastal cliff in question. Among them a special case of filtration, i.e. infiltration should be mentioned. In order to determine a solution of Eq. 1, at least one condition should be added. However, in view of that we are to consider the problem in the set $\Omega=<0, \infty) \times<0, \infty)$, i.e. for $(z, t) \in \Omega$, it is necessary to add to Eq. (1) initial-boundary conditions in the following form:

$$
\begin{gathered}
u(z, 0)=\varphi_{0}(z), \\
u(0, t)=\Psi_{0}(t), u(\infty, t)=\psi_{1}(t),
\end{gathered}
$$

In the considered case for the qualitative analysis it is sufficient to assume that in Eq. (1), K $\in \operatorname{Ker} \frac{\partial}{\partial z}, D(u)=$ const and, additionally, that the above given functions $\varphi_{0}(z), \psi_{0}(t)$, $\psi_{1}(t)$ constitute constants equal to $\varphi_{0}, \psi_{0}, \psi_{1}$, respectively. The so obtained initial-boundary problem can be solved with the use of the generalized calculus of operators $[6,7,8]$. Making use of two operations: $S_{1}=-D \frac{\partial}{\partial t}$ and $S_{2}=D \frac{\partial}{\partial z}\left(D \frac{\partial}{\partial z}\right)$, we can write the modified Eq. (1) in an equivalent form as follows:

$$
S_{1} u+S_{2} u=0
$$


The solution of the differential equation (4) with the conditions (2), (3) in the operators domain has the form as follows :

$$
u(z, t=) \frac{T_{2} \varphi_{0}+T_{1} s_{2} u}{T_{1}+T_{2}}=\frac{p_{1} \varphi_{0}+p_{2} s_{2} u}{p_{1}+p_{2}}
$$

where the operations $T_{1}, T_{2}, S_{2}$ are determined by the operations $S_{1}, S_{2}$, and $p_{1}, p_{2}$ are the generalized Heaviside operators for the operations $T_{1}, T_{2}$, [6, 7].

As results from Eq. (5), the decisive (from the point of view of the qualitative analysis of the problem ) impact on the course of the phenomenon had the underground water flow with the critical speed.

The causative factor was rainfall water migrating within the ground, which was accumulated in more permeable ground layers supported by less permeable ones; such conclusion also results from the mathematical analysis of the problem in question.

\section{NATURAL PHENOMENA}

The analyzed area of the moraine hill is characteristic of occurrence of local depressions ( de-levelling ) of $15 \div 30 \mathrm{~m}$ in depth. The de-levelling is associated with occurrence of slopes with $30^{\circ}$ steepness. Such large de-levelling results in susceptibility of this area to occurrence of ground mass movements manifested in local landslides of a natural character [4].

The geological data [10] confirm that in the area of Kamienna Góra there are formations stratified by ground layers of different filtration ratios. In this area no free surface pools of groundwater occur, but ground layers are supplied with rainfall and runningoff waters from a significant part of the area of the moraine hill Kamienna Góra. If we correlate this fact with the occurrence of the formations stratified by grounds of different filtration ratios, we will getstrong argument that the landslide in question was caused by the watering of the ground and, consequently, the loss of its strength properties associated with the watering.

According to the data of the Institute of Meteorology and Water Economy (IMiGW) in Gdynia, a rainfall of almost $14 \mathrm{~mm}$ happened 96 hours before occurrence of the landslide. The excessive, long-lasting rainfall water flow into the ground could result in watering the ashy ground layers, lowering their strength parameters as well as exceeding the critical water pressure in ground pores, resulting from the hydraulic piping flow as well as local liquefaction of ground masses.

\section{LAND DEVELOPMENT}

With land development there are associated anthropogenic factors of changes introduced in urban areas of Gdynia. The infrastructure built in the area of Kamienna Góra resulted in an increased destruction of its natural landform and natural elements protecting slopes against landslide. Among various conditions affecting escarpment stability, there is enumerated a. o. flora which acts also deep into ground due to its root system [12]. Trees and bushes present on the slopes affect water circulation conditions within the ground, causing its water permeability greater in the neighbourhood of the root system. This way, the root system is capable of decreasing excessive water pressure in ground pores by a controlled outflow of water from the ground. Moreover, water demand from the side of plants necessary for their biological processes contributes in lowering ground humidity in their neighbourhood. Additionally, due to transpiration, in the root system area there occur compressive stresses which increase effective stresses in the ground and its shear strength. The substantial influence of plants on escarpment stability is also associated with their root systems which play the role of the so called natural ground reinforcement as the roots are capable of transferring tension stresses, increasing this way ground shear strength that is associated with occurrence of apparent cohesion.

For several years before the landslide event, a devastation of the existing stand of trees has been observed. As a result, a lack of the natural factor holding the ground on the slope has been introduced. The attached photographs reveal a wastage of the stand of trees in this area (Fig. 7a, Fig. 7b).

a)

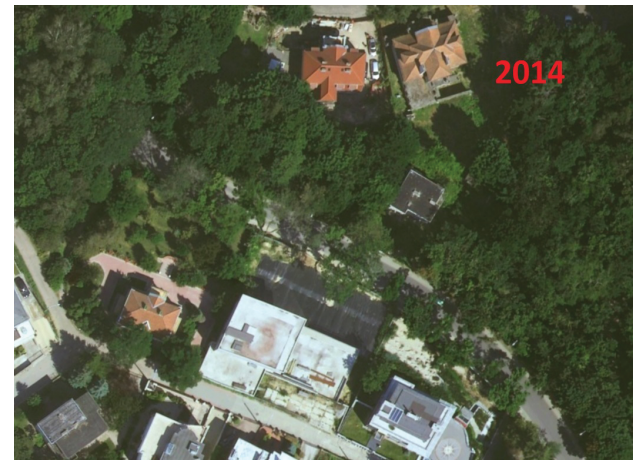

b)

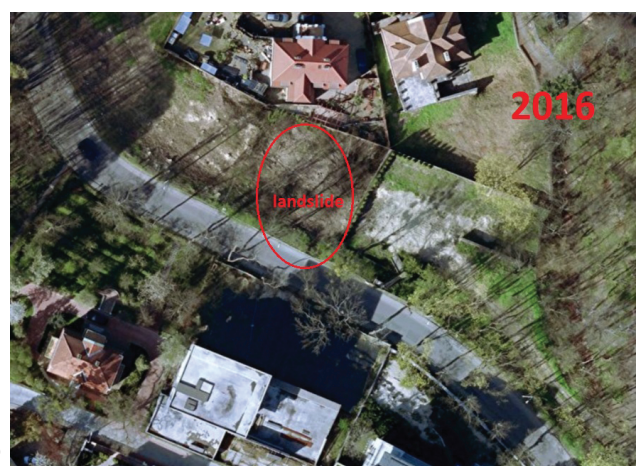

Fig. 7. Changes in the stand of trees within the landslide, which occurred between the years 2014 and 2016, (Aerial photographs shot by MGGP AERO)

\section{BUILDING INFRASTRUCTURE}

The urban and road infrastructure has intensively entered the steep and high edge of the slope where the landslide has occurred later. Unfortunately, in the urban development projects a rather low significance has been attached to the 
question of channelling the rainfall waters and protecting the slope against sliding. According to the data of the State Geological Institute, the area of the moraine hill Kamienna Góra is classified as a terrain endangered by landslides and exposed to periodical impacts of underground water coming from intensive rainfalls [10].

In the opinion of inhabitants of nearby houses, streams of water appear very fast during heavy rainfalls. It means that the drainage systems of the terrain are ineffective. There is a lack of collectors for the water which appears during heavy rainfall. Roadways are not fitted with channels and drain pipes to discharge rainfall water, and, as a result, the water flows over kerbs and pavements, flooding this way slopes and watering the ground locally. Also, the fact of substantial hardening the nearby terrain surface is not without a significance as the water coming from a long-lasting rainfall is not able to seep gently into the ground, and in consequence, water streams flow along the streets.

\section{ANTHROPOGENIC TRANSFORMATION OF THE TERRAIN}

Beginning from the year 2009, in the landslide area a dwelling house has been built. Many earthworks impairing ground structure have been conducted, natural flow channels of underground water have been cut off or changed. After completing foundation trench, there were observed seepages of water from the ground. During building works a significant water inflow to the trench was noted, and in spring periods it was continuous.

As neither storage reservoirs nor drainage for discharging the ground water were made, the water concentrated at the foot of slope in the site of the damage. According to the project, around the house a French drainage system was provided for discharging rainfall water. This is a solution in which a mineral aggregate carrying water away is wrapped in a geo-unwoven cloth which serves as a filtration layer. The French drainage fulfils its role correctly if only it is connected to a reservoir of a sufficient capacity or retention. In case of an extensive ground water flow a French drainage, if not connected to an appropriate storage reservoir, may be inefficient due to its low retention capability and even hazardous in view of possible infiltration of stored rainfall water into earth, that results in decreasing the strength parameters of the ground, especially in the case of the ground profile in question where layers of ashy ground (ashes, clayey sands, ashy sands) especially exposed to a loss of strength parameters as a result of watering, occur.

In the building site a complete drainage system has not been made. Till the break in the building works only a part of band drainage has been worked out. No storage reservoir, the crucial element of the drainage system, intended for storing the rainfall water, has been built. The completion of only a part of the rainfall water intake and storage system had more detrimental effect onto stability of the slope than a complete lack of it. The drained rainfall water was directed straight into the ground, penetrating its deeper layers, directly.

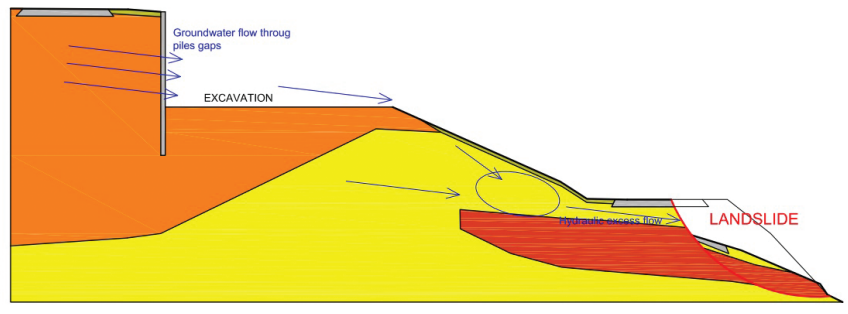

Fig. 8. Direction of hydraulic excess flow under the road of Sienkiewicz street.

Over the entire cliff area there is legally forbidden to discharge the rainfall water off the buildings and hardened surface areas directly into the ground because the terrain is deemed susceptible to landslides [10]. Till the occurrence of slope damage, the rainfall waters were discharged directly into the ground. It resulted in a degradation of its strength parameters in the analyzed area, especially in places where ashy ground layers were present. The damage mechanism is highlighted in Fig. 8.

\section{CONCLUSIONS}

Any of the above specified factors itself probably would not be able to cause the landslide. However their cumulative effect and coincidence of unfavourable events finally resulted in the building damage.

The removal of flora from the escarpment area of the plot in question and neighbouring plots exposed the terrain to intensive surface erosion and increased infiltration of rainfall water into the ground, that resulted in the ground strength lowering. Additionally, a lack of transpiration causes that water is not taken up by the plant root system and in the surrounding ground there do not exist respective compression stresses resulting from sucking the water by plants.

Lack of any intake system of rainfall water from the roadway and areas of hardened surface makes water infiltration rate into the ground greater.

The break in the building works, which was introduced without completing realization of the drainage system, resulted in penetration of the taken-in rainfall water deep into the slope and its accumulation over the damage site, that caused a decrease in the ground strength parameters as a consequence of watering the ground.

\section{REFERENCES}

1. Bird E.: Encyclopedia of the World's Coastal Landforms. Springer Science \& Business Media 2010.

2. Bolton Seed H.: Design problems in Soil Liquefaction. Journal of Geotechnical Engineering Vol. 113, Issue 8, 1987.

3. Fread D. L.: Flood routing. In: Handbook Hydrology, edited by D. Maidment, Chapter 10. McGraw-Hill, New York 1993. 
4. Komar P.D.: Wave erosion of a massive artificial coastal landslide. Earth Surface Processes and Landforms 1998.

5. Lee E., Meadowcroft I., Hall J., Walkden M.: Coastal landslide activity: a probabilistic simulation model. Bulletin of Engineering Geology and the Environment, Vol. 61, Issue 4, pp. 347-355, 2002.

6. Mieloszyk E.: Application of non-classical operational calculus to solving some boundary value problem. Integral Transforms and Special Functions. Vol 9, No 4. 2000.

7. Mieloszyk E.: Non-classical operational calculus in application to generalized dynamical systems. Polish Academy of Sciences. Scientific Publishers, Gdansk. 2008.

8. Milewska A.: A solution of non-linear differential problem with application to selected geotechnical problems. Archives of Civil Engineering, LVIII, 2011.

9. Ossowski R.: Environmental Aspects of Coastal Earth Structures Made of Soil-Ash Composites. Polish Maritime Research. Vol. 24, No S1 (93), 2017, pp. 166-173.

10. State Geological Institute: Database of geological engineering data together with geological engineering atlas for the Threecity agglomeration Gdańsk-Sopot-Gdynia (in Polish). Publ. Państwowy Instytut Geologiczny (State Geological Institute) - Państwowy Instytut Badawczy (State Research Institute), November 2007.

11. Sikora Z., Subotowicz W., Wyroślak M., Ossowski R.: Failure States of Coastal Cliff in Jastrzębia Góra. 27 ${ }^{\text {th }}$ Scientific Technical Conference on Building Damages. Międzyzdroje 2015.

12. Ziemer R. R.: Root and the stability of forested slopes. I.A.H.S. Publ. No. 132, 1981.

\section{CONTACT WITH THE AUTHOR}

\section{Eligiusz Mieloszyk}

Gdansk University of Technology Faculty of Civil and Environmental Engineering, Department of Rail Transportation and Bridges

Poland

\section{Mariusz Wyroślak}

Gdansk University of Technology Faculty of Civil and Environmental Engineering, Department of Geotechnics Geology and Marine Civil Engineering

Poland 